\title{
Sistem Manajemen Percetakan pada CV. Sumber Bahagia Kreasindo Jakarta dengan Metode Prototyping
}

\author{
Rusydi Umar¹, Purwono², Muhammad Nasir Hafidz ${ }^{3}$, Kharis Hudaibiy Hanif ${ }^{4}$, Fijaya \\ Bima Dwi Sakti ${ }^{5}$, Dewi Astria Faroek ${ }^{6}$ \\ 1,2,3,4,5,6Magister Teknik Informatika, Universitas Ahmad Dahlan, Kampus III UAD, \\ Jl. Prof. Dr. Soepomo, Janturan, Umbulharjo, Yogyakarta \\ ${ }^{1}$ rusydi_umar@rocketmail.com, 2purwono190807015@webmail.uad.ac.id, \\ 3m1907048019@webmail.uad.ac.id, 4kharis1907048017@webmail.uad.ac.id, \\ 5Fijaya1907048016@webmail.uad.ac.id,6dewi1907048014@webmail.uada.ac.id
}

\begin{abstract}
Companies that have two or three more people with an agreement between them is the understanding of the Vennootschap Commanditaire (CV). There are various kinds of CVs that are developing at this time, namely agricultural companies, industry, trade, extractives, and service companies. CV. Sumber Bahagia Kreasindo is a company that offers printing services located in Central Jakarta. Increasingly, customers in the company are increasing and expanding, so they need a system that can recapitulate order data from customers to be more efficient and systematic. The rapid development of technology today, so that it can help employees who previously wrote orders manually. Can write orders through the website. The system makes it easy for employees to see the order process from customers,
\end{abstract}

Keywords: Prototyping, CV. Sumber Bahagia Kreasindo, Commanditaire Vennootschap.

\begin{abstract}
Abstrak
Perusahaan yang mempunyai dua atau tiga orang lebih dengan adanya perjanjian diantara mereka merupakan pengertian dari Commanditaire Vennootschap (CV). Ada berbagai macam CV yang berkembang saat ini yaitu perusahaan agraris, indsutri, dagang, ektraktif, dan perusahaan jasa. CV. Sumber Bahagia Kreasindo merupakan perusahaan yang menawarkan jasa percetakan yang bertempat di Jakarta Pusat. Semakin tahun pelanggan di perusahaan itu semakain bertambah dan meluas sehingga membutuhkan suatu sistem yang dapat merekap data order dari pelanggan agar lebih efisien dan sistematis. Semakin berkembang pesatnya teknologi saat ini, sehingga dapat membantu karyawan yang tadinya menulis pesanan secara manual. Dapat menulis pesanan lewat website. Sistem tersebut memudahkan karyawan untuk melihat sampai mana proses pesanan dari pelanggan,
\end{abstract}

Kata kunci: Prototyping, CV. Sumber Bahagia Kreasindo, Commanditaire Vennootschap.

\section{PENDAHULUAN}

CV. Sumber Bahagia Kreasindo merupakah sebuah perusahaan yang menawarkan jasa percetakan yang terletak di Jakarta Pusat. Berbagai macam jasa yang ditawarkan meliputi cetak banner, brosur, spanduk, buku, booklet, kalender, dan semua yang terkait dengan media cetak. Perusahaan ini sudah menjalankan usahanya lebih dari 10 tahun. Pelanggan perusahaan tidak hanya dari dalam kota, namun sudah merambah hampir di seluruh perkotaan besar di Indonesia seperti Bandung, Semarang, Surabaya, Bandar Lampung, Yogyakarta dan sebagainya. Banyaknya pelanggan yang terus bertambah memicu dibutuhkannya sebuah sistem yang mampu memanajemen order 
percetakan agar pelayanan yang dihasilkan dapat berjalan lebih efektif dan efisien. Rekap data order yang berjalan saat ini masih dilakukan secara manual sehingga berakibat pada beberapa kesalahan seperti adanya kesalahan produksi hingga kesalahan pencatatan keuangan.

Kemajuan teknologi yang terus berkembang membuat semua urusan menjadi semakin mudah [1]. Saat ini teknologi semakin banyak membantu dalam menyelesaikan setiap kegiatan ataupun pekerjaan seseorang. Bahkan setiap aktivitas yang dilakukan selalu melibatkan teknologi, misalnya seperti berinteraksi, mengolah data, memberikan informasi, mengambil sebuah keputusan dan masih banyak lagi [2]. Salah satu teknologi yang dapat dimanfaatkan adalah penggunaan media website yang dapat menghubungkan berbagai pengguna dengan satu portal dalam bentuk situs untuk saling bertukar informasi [3]. CV. Sumber Bahagia Kreasindo dapat memanfaatkan media website sebagai sebuah sistem yang mampu memanajemen order percetakan dari pelanggannya. Kesalahan manajemen yang ditimbulkan dalam perusahaan percetakan menggunakan metode konvensional diharapkan dapat diselesaikan.

Beberapa penelitian pernah dilakukan terkait dengan pengembangan website percetakan seperti yang dilakukan oleh [4] hasil yang diperoleh adalah perusahaan percetakan yang menggunakan media website mampu menjangkau pasar yang lebih luas, selain itu juga adanya kemudahan dalam memanajemen dalam pengolahan data dan laporan. Hal serupa juga sudah dilakukan oleh [5] dengan menarik kesimpulan bahwa website percetakan dapat memudahkan dalam memanajemen data laporan. Yang paling menarik adalah penelitian tentang marketplace percetakan [6] yang dapat menghubungkan pelanggan dengan percetakan menjadi semakin mudah karena percetakan tersebar diseluruh wilayah dan dapat diakses secara online hingga kemudahan dalam layanan antar untuk hasil produk percetakan.

Penelitian ini akan berfokus kepada kebutuhan pengguna, jadi akan digunakan metode prototype dalam pengembangannnya. Dengan metode prototyping implementasi sistem menjadi semakin mudah karena adanya peran aktif dari pengguna [7]. Website manajemen percetakan yang akan dibangun meliputi kegiatan transaksi utama pengguna yaitu order, produksi, pengiriman, manajemen vendor dan produk serta keuangan. Teknologi website yang digunakan adalah framework Codeigniter. Framework ini dipilih karena dapat mempercepat dalam pembuatan sebuah website [8].

\section{METODOLOGI PENELITIAN}

\subsection{Metode Pengumpulan Data}

Data merupakan sebuah hal yang paling primer dalam penelitian karena data sangat berpengaruh pada kualitas dan hasil penelitian. Beberapa metode pengumpulan data yang dapat dilakukan dalam membuat sistem antara lain dengan melakukan wawancara dan observasi [9][10][11]. Wawancara dilakukan dengan pemilik perusahaan yaitu Kiki Irawan, S.Kom, 
hingga mendapatkan kebutuhan sistem yang akan dibangun. Observasi dilakukan secara langsung pada lokasi perusahaan dan didapatkan beberapa bidang terkait dengan sistem ini antara lain adalah data pelanggan, vendor, pengguna, produk, order, produksi dan keuangan.

\subsection{Metode Pengumpulan Data}

Untuk mengembangkan sistem manajemen percetakan digunakan model prototype. Model prototype bertujuan agar pengguna dapat sering berinteraksi dengan prototype yang diajukan. Prototype akan mengajukan versi dasar yang dapat dikembangkan menjadi lebih besar sesuai dengan kebutuhan pengguna [12]. Tahap-tahap dalam pengembangan metode prototyping antara lain [13] [14] adalah:

a) Communication

Pada tahap komunikasi, dilakukan dengan melakukan wawancara dan observasi kepada pemilik perusahaan. Dalam tahap ini dikumpulkan kebutuhan dan permasalahan pengguna sehingga didapatkan garis besar secara keseluruhan sistem yang akan dibuat.

b) Quick Plan and Modeling Quick Design

Pada tahap ini berfokus pada tampilan dari sistem (interface) serta output yang digunakan oleh pengguna.

c) Construction of Prototype

Dibangunya model perencanaan dari tahapan sebelumnya.

d) Deployment Delivery and Feedback

Prototype kemudian diserahkan kepada pengguna untuk dilakukan uji coba dan evaluasi. Pengguna akan memberikan feedback mengenai prototype yang sudah dibuat. Feedback akan digunakan sebagai acuan perbaikan dari prototype hingga menghasilkan sebuah sistem yang sesuai dengan kebutuhan pengguna.

Berdasarkan metode prototyping, maka dalam penelitian ini akan dilakukan tahapan penelitian sebagai berikut:

1) Melakukan pengumpulan data dengan metode wawancara dan observasi.

2) Membuat Use Case, sequence, activity, class diagram dan ERD

3) Membuat rancangan tampilan website

4) Melakukan implementasi rancangan dan pembuatan prototype.

Penyerahan prototype kepada pengguna dan mendapatkan umpan balik. Jika ada hal yang harus diperbaiki, maka prototype akan diperbaiki sesuai kebutuhan pengguna. 


\section{HASIL DAN PEMBAHASAN}

\subsection{Analisis Kebutuhan Sistem}

Setelah melakukan wawancara dan observasi maka didapatkan kebutuhan sistem oleh pengguna adalah sebagai berikut:

a) Sistem dapat mengelola data pelanggan

1. Sistem dapat menambah data pelanggan

2. Sistem dapat menyimpan datapelanggan

3. Sistem dapat mengubah data pelanggan

4. Sistem dapat menghapus data pelanggan

5. Sistem dapat mencetak data pelanggan

b) Sistem dapat mengelola data vendor

1. Sistem dapat menambah data vendor

2. Sistem dapat menyimpan data vendor

3. Sistem dapat mengubah data vendor

4. Sistem dapat menghapus data vendor

5. Sistem dapat menambah data produkvendor

6. Sistem dapat menyimpan data produkvendor

7. Sistem dapat mengubah data produkvendor

8. Sistem dapat menghapus data produkvendor

c) Sistem dapat mengelola data produk

1. Sistem dapat menambah data kategoriproduk

2. Sistem dapat menyimpan data kategori produk

3. Sistem dapat mengubah data kategoriproduk

4. Sistem dapat menghapus data kategoriproduk

5. Sistem dapat menambah data produk

6. Sistem dapat menyimpan data produk

7. Sistem dapat mengubah data produk

8. Sistem dapat menghapus data produk

d) Sistem dapat mengelola data order

1. Sistem dapat menambah data order

2. Sistem dapat menyimpan data order

3. Sistem dapat mengubah data order

4. Sistem dapat menghapus data order

e) Sistem dapat mengelola data produksiorder

f) Sistem dapat mengelola data keuangan

1. Sistem dapat menambah kas masuk

2. Sistem dapat menyimpan kas masuk

3. Sistem dapat mengubah kas masuk

4. Sistem dapat menghapus kas masuk

5. Sistem dapat menambah kas keluar

6. Sistem dapat menyimpan kas masuk

7. Sistem dapat mengubah kas masuk

8. Sistem dapat menghapus kas masuk

9. Sistem dapat melihat kas keseluruhan 


\subsection{Perancangan Sistem}

\subsubsection{Use Case Diagram}

Dalam skenario Use Case diagram pada website manajemen percetakan memiliki empat aktor adalah admin, sales, operasional dan finance. Admin bertugas untuk untuk memanajemen semua transaksi yang masuk serta mengawasi semua kegiatan perusahaan seperti melihat order, proses produksi, produk dari vendor hingga keuangan. Admin memiliki hak mutlak untuk menambah, menyimpan, mengubah atau menghapus segala data pada website.

Aktor sales memiliki hak untuk memanajemen data seperti pelanggan, kategori produk produk serta order cetak berdasarkan pelanggan yang dia dapatkan. Aktor operasional bertugas sebagai orang yang menjalankan proses produksi dari order cetak yang masuk dari sales. Aktor operasional memberikan informasi progress dari setiap proses percetakan dari pracetak, proses cetak, finishing hingga pengiriman barang. Aktor keuangan bertugas untuk memanajemen keuangan dari kas masuk, kas keluar hingga mencetak data laporan keuangan.

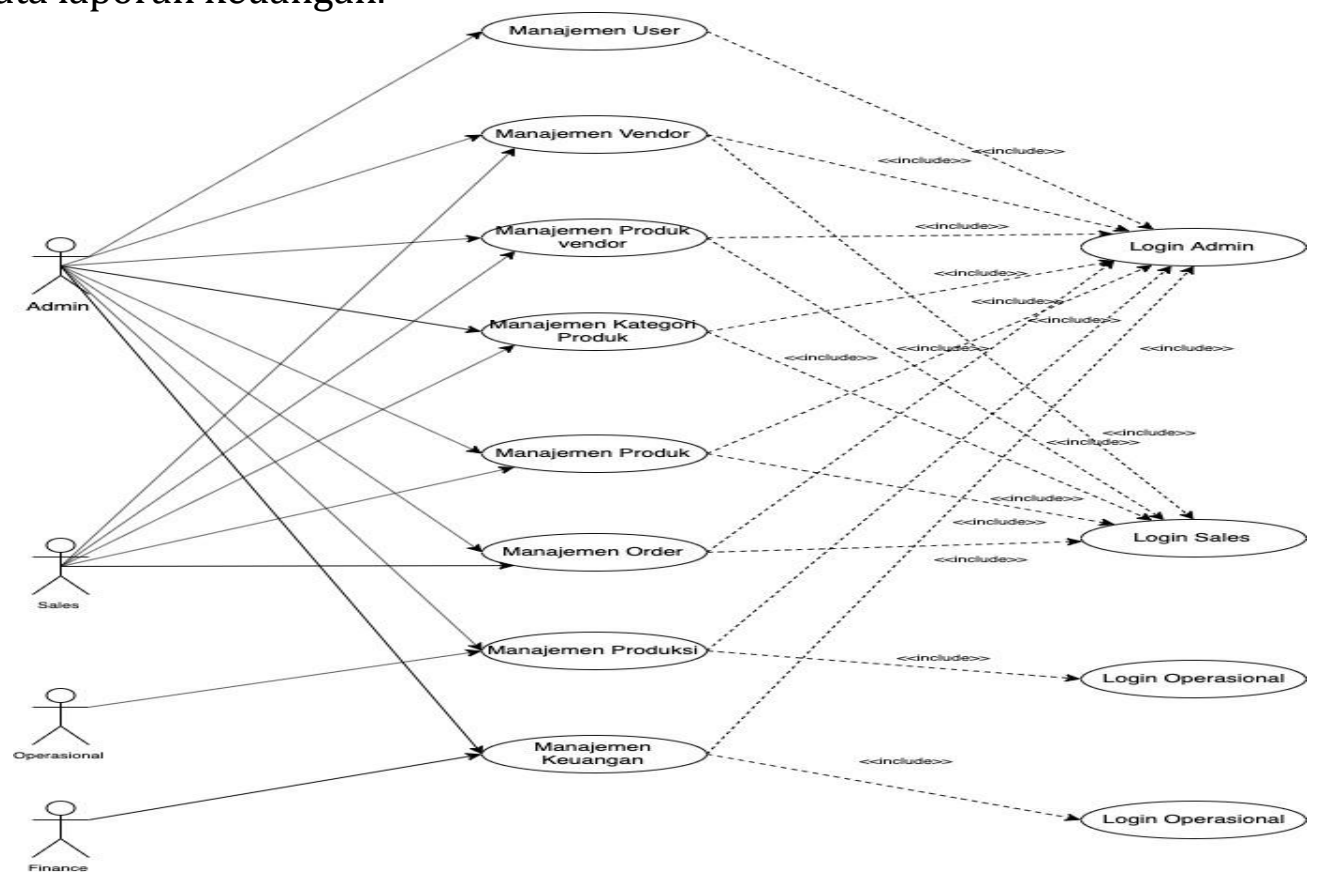

Gambar 1. Use Case Website Manajemen Percetakan

\subsubsection{ERD (Entity Relationship Diagram)}

Untuk menggambarkan entitas-entitas yang ada, pada penelitian ini menggunakan ERD (Entity Relationship Diagram). Gambar 2 menunjukan entitas-entitas yang terdapat pada website manajemen percetakan pada CV. Sumber Bahagia Kreasindo. Entitas-entitas tersebut antara lain adalah: admin, pelanggan, sales, finance, operasional, vendor, produk vendor, produk, kategori produk, order, proses produksi, keuangan, kas masuk, kas keluar, pracetak, proses cetak, finishing dan delivery. 


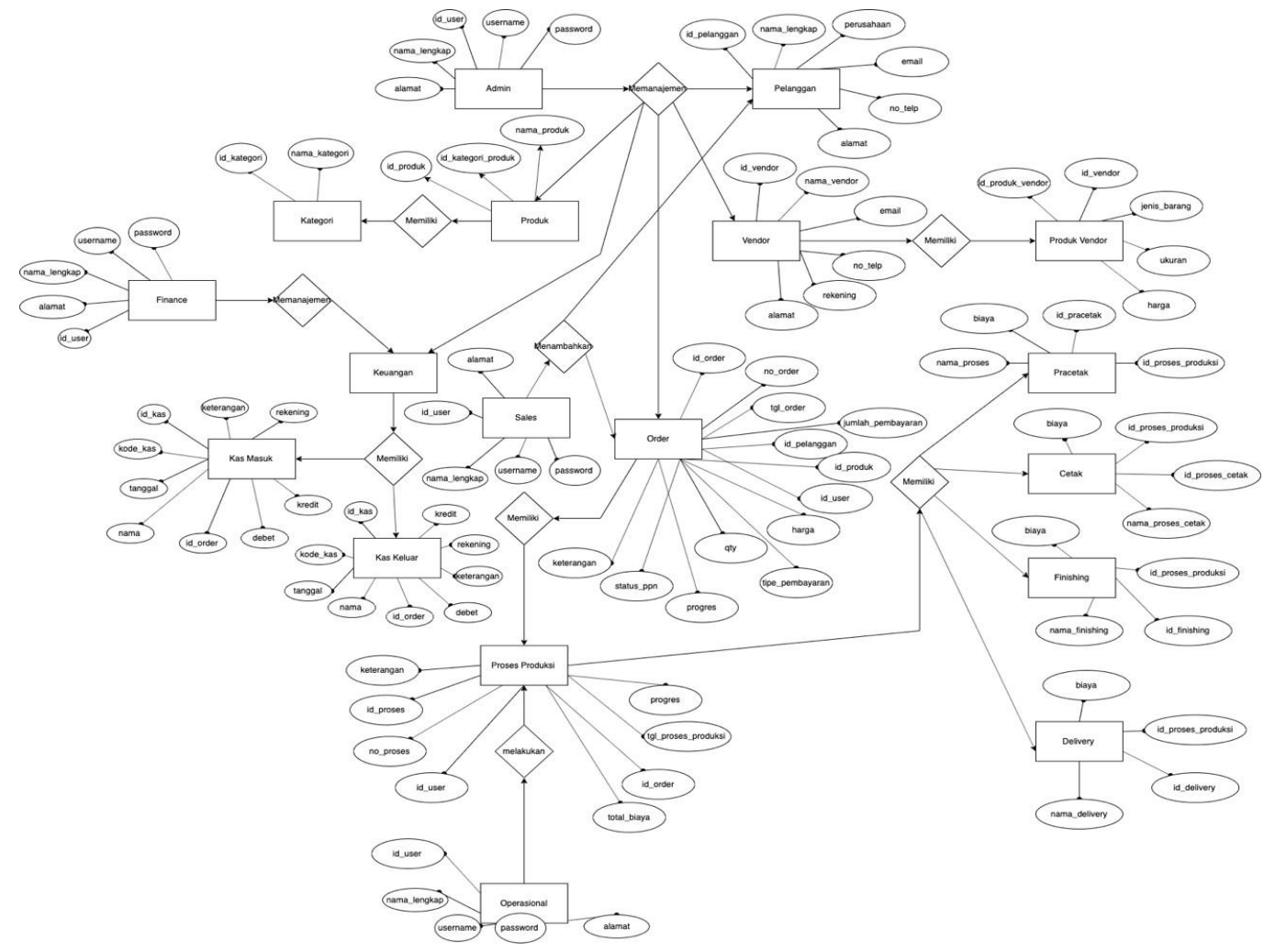

Gambar 2. ERD Website Manajemen Percetakan

\subsection{Implementasi Prototype}

Tahap implementasi tahapan pengembangan setelah sebelumnya dibuat perencanaan. Pada tahap ini dilakukan pengkodean sistem.

\subsubsection{Form Login}

Untuk mengakses sistem diperlukan sebuah pintu masuk dari beberapa aktor yang berperan pada sistem. Login dapat ditemukan pada saat pertama kali mengakses sebuah Halaman website. Gambar 3 merupakan form login dimana pengguna dapat memasukan username, password dan akses level untuk masuk ke dalam sistem.

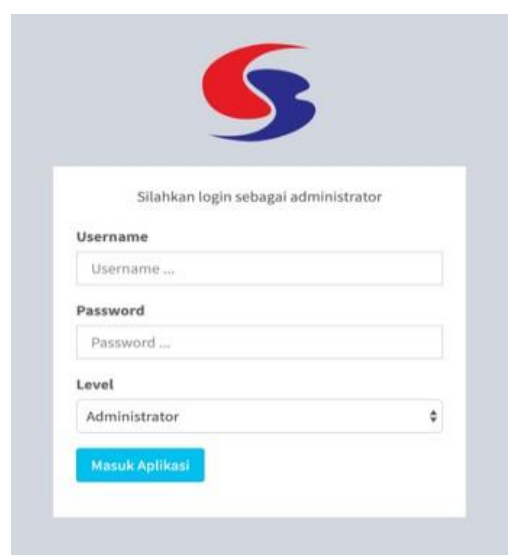

Gambar 3. Form Login 


\subsubsection{Form Manajemen Vendor}

Menu pelanggan berisi tentang data pelanggan yang telah melakukan order pada CV. Sumber Bahagia Kreasindo. Pelanggan ditambahkan oleh bagian sales perusahaan. Pada gambar 4 merupakan halaman pelanggan dengan sub menu seperti tambah, edit dan hapus pelanggan.

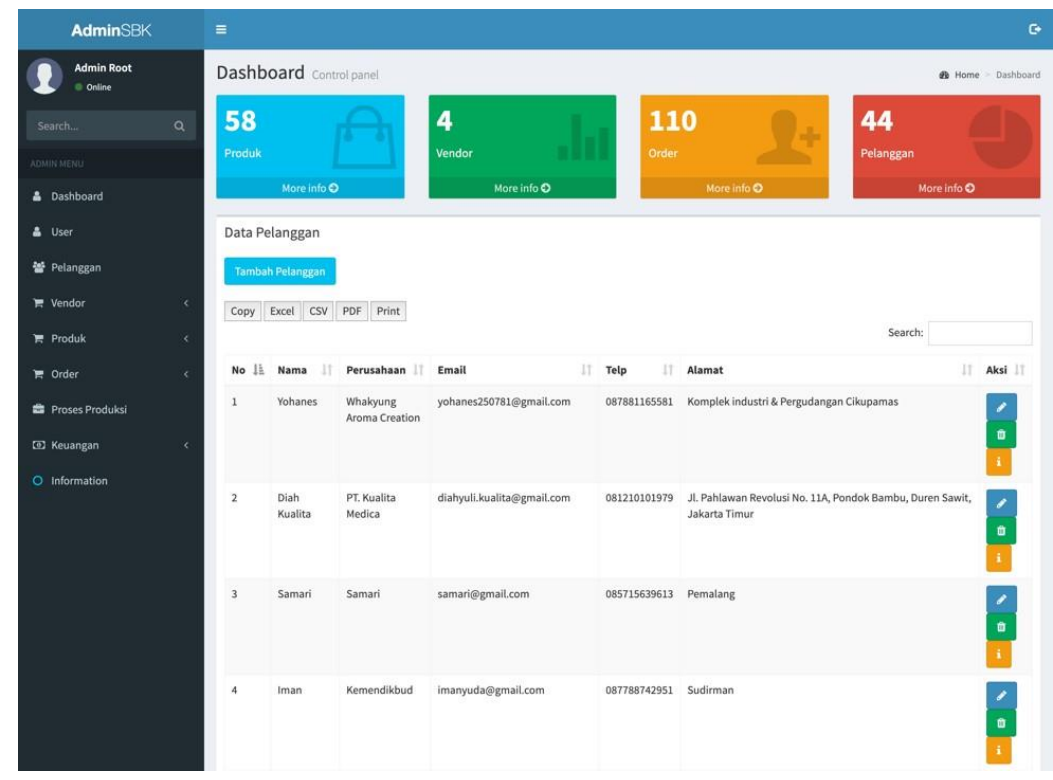

Gambar 4. Tampilan Data Pelanggan

\subsubsection{Form Manajemen Vendor}

Pada halaman admin, terdapat menu "Vendor" yang berfungsi untuk menampilkan data vendor. Di dalam menu "vendor" juga terdapat menu produk vendor seperti bahan-bahan yang digunakan oleh percetakan antara lain kertas cetak, plat ataupun stiker. Gambar 5 merupakan halaman menu "vendor" di dalamnya terdapat sub menu untuk melakukan manajemen data vendor seperti tambah, edit, hapus data vendor.

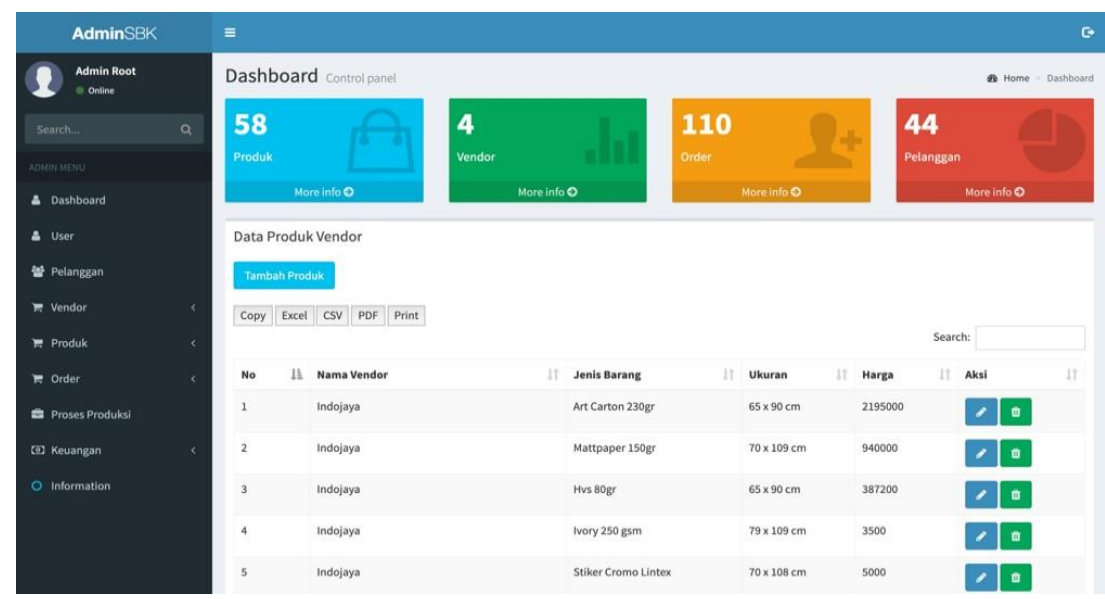

Gambar 5. Tampilan Menu Vendor 


\subsubsection{Form Manajemen Produk}

Pada halaman produk berfungsi untuk menampilkan data produk yang bisa dikerjakan oleh CV. Sumber Bahagia Kreasindo. Gambar 6 merupakan halaman menu "Produk" didalamnya terdapat sub menu untuk melakukan manajemen data produk seperi tambah, edit dan hapus produk. Setiap produk memiliki kategori produk yang dapat ditambahkan pada menu kategori produk.

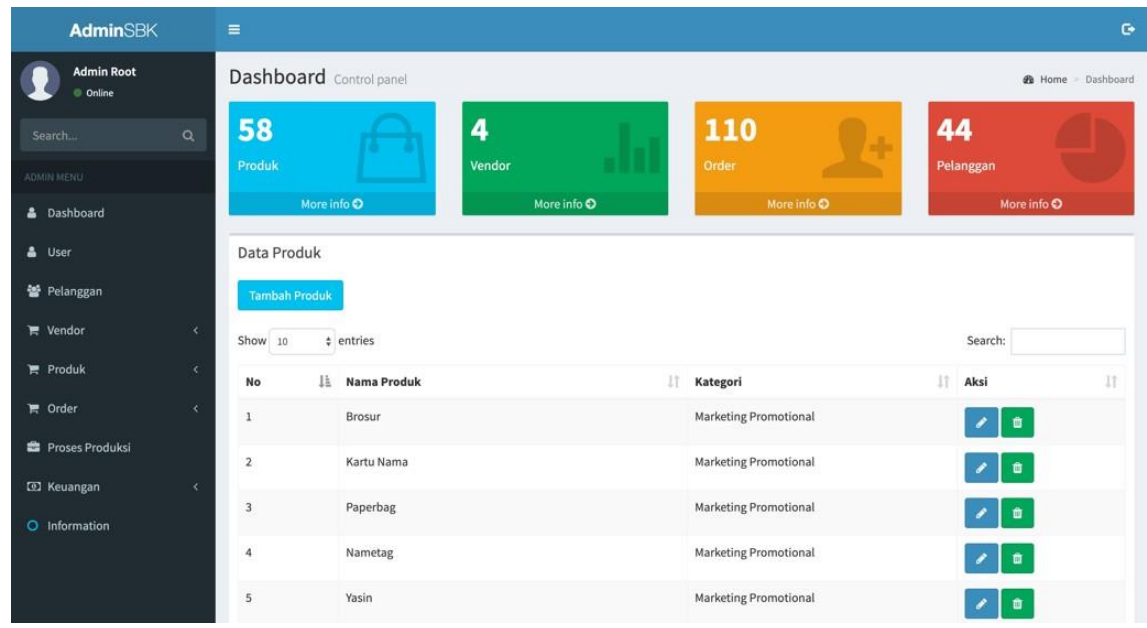

Gambar 6. Tampilan Data Produk

\subsubsection{Form Manajemen Order}

Halaman manajemen order berisi setiap orderan masuk dari pelanggan. Gambar 7 merupakan halaman order. Order yang masuk berisi informasi seperti tanggal order, harga order hingga progress pekerjaan cetak. Pada menu ini terdapat submenu seperti tambah, edit dan hapus order yang dapat dilakukan oleh admin dan sales.

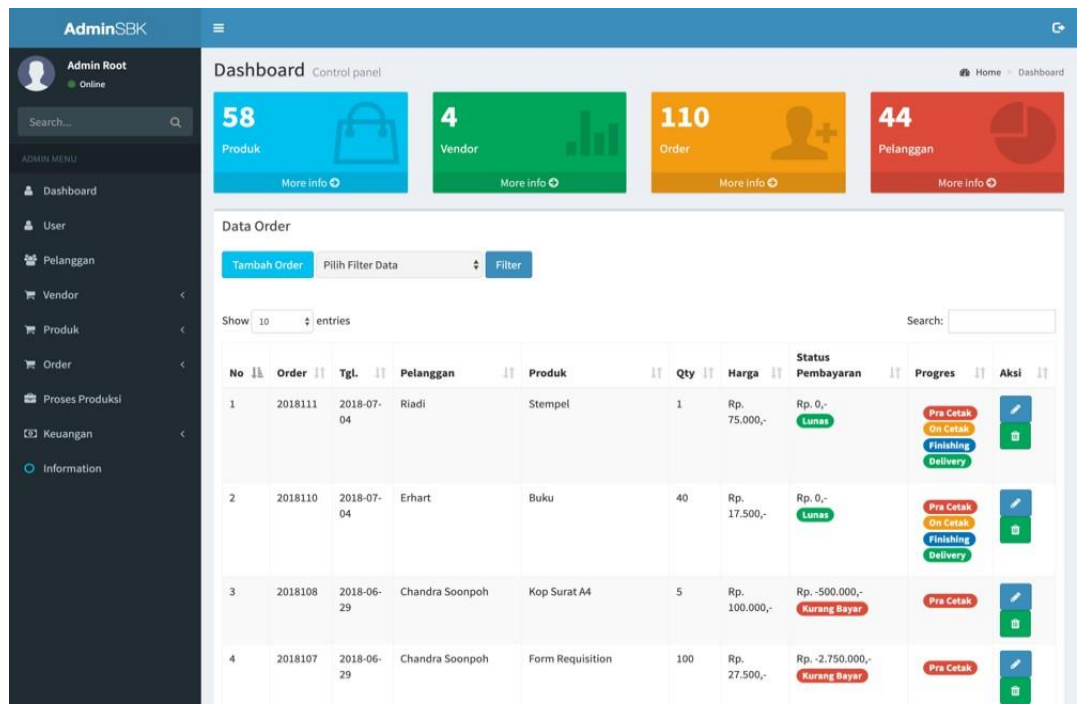

Gambar 7. Tampilan data order percetakan 


\subsubsection{Form Manajemen Produksi}

Setiap orderan yang masuk akan diproses oleh bagian operasional pada menu proses produksi. Pada proses ini bagian operasional akan melaporkan proses percetakan kepada admin dan sales. Gambar 8 menunjukan tampilan order yang sedang diproses oleh bagian operasional meliputi pracetak, proses cetak, finishing dan delivery.

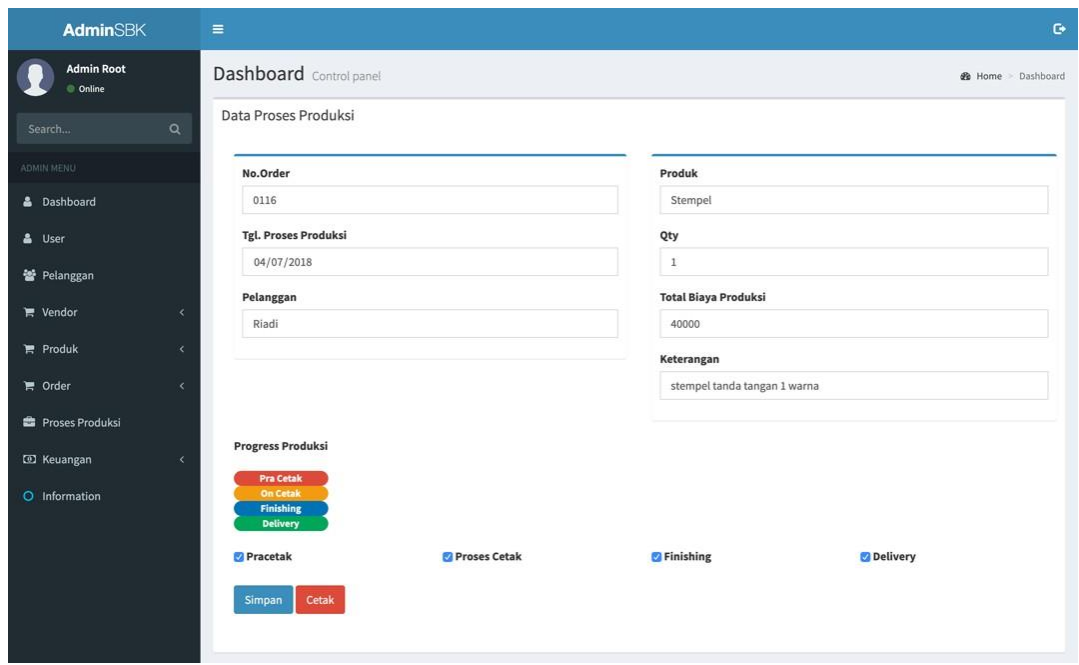

Gambar 8. Tampilan data proses produksi cetak

\subsubsection{Form Manajemen Keuangan}

Data keuangan berisi data kas masuk dan kas keluar. Kas masuk adalah pemasukan dari setiap order yang masuk, sedangkan kas keluar dikeluarkan oleh bagian finance ketika membutuhkan biaya produksi. Pada Gambar 9 adalah tampilan rekap keuangan perusahaan di dalamnya terdapat sub menu untuk menambahkan kas masuk atau keluar. Setiap sub menu memilki fungsi tambah, edit dan hapus data.

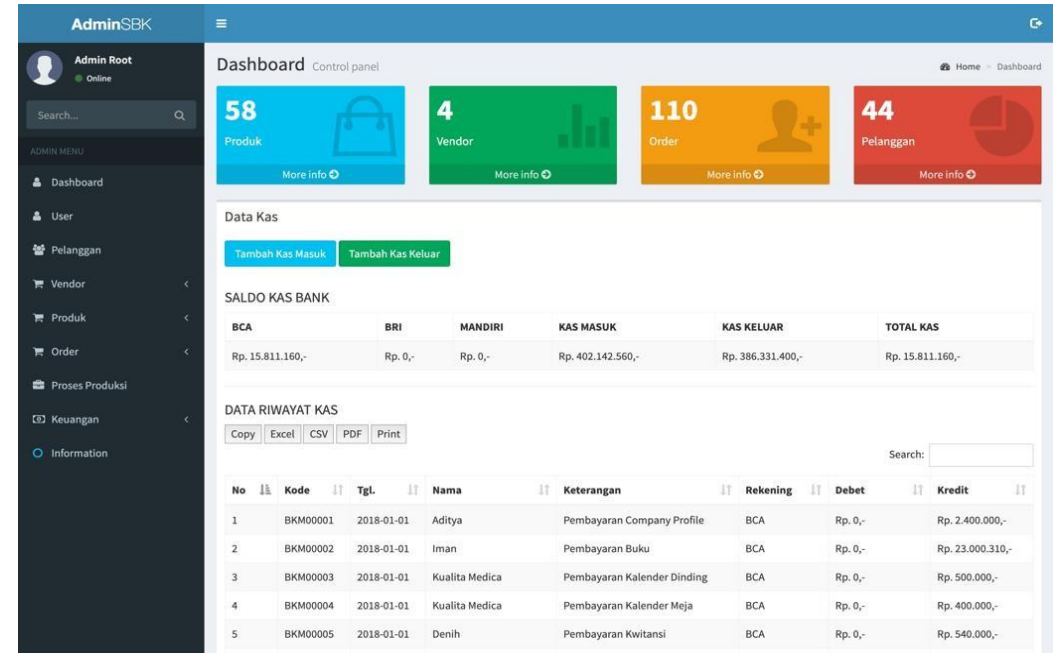

Gambar 9. Tampilan data kas secara keseluruhan 


\subsection{Pengujian Protoytype I}

Pengujian produk ini dilakukan dengan metode Black Box dan UAT. Berikut ini adalah tabel dari hasil pengujian I menggunakan black box.

Tabel 1. Pengujian Black Box

\begin{tabular}{|c|c|c|c|}
\hline No & Fungsi & Keterangan & Status \\
\hline 1 & Login dan Logout & $\begin{array}{l}\text { Deskripsi: } \\
\text { Form yang digunakan untuk masuk pada } \\
\text { halaman dashboard sistem. } \\
\text { Prosedur Pengujian: } \\
\text { a. Login: User memasukan username, } \\
\text { password dan memilih level akses, jika } \\
\text { benar maka akan masuk pada halaman } \\
\text { dashboard sistem } \\
\text { b. Logout: User menekan tombol logout. }\end{array}$ & Sukses \\
\hline 2 & $\begin{array}{l}\text { Manajemen } \\
\text { Pelanggan }\end{array}$ & $\begin{array}{l}\text { Deksripsi: } \\
\text { Form yang digunakan untuk memanajemen } \\
\text { data pelanggan yang masuk. } \\
\text { Prosedur Pengujian: } \\
\text { a. Tambah Pelanggan: User menekan } \\
\text { tombol tambah pelanggan. User } \\
\text { memasukan data- data pelanggan, jika } \\
\text { berhasil maka data akan tersimpan pada } \\
\text { database dan muncul pada halaman } \\
\text { pelanggan. } \\
\text { b. Ubah Pelanggan: User memilih salah satu } \\
\text { pelanggan yang akan diubah datanya. } \\
\text { User kemudian mengubah data lalu } \\
\text { menekan tombol update. Jika berhasil } \\
\text { data akan terupdate pada database dan } \\
\text { data akan terganti. } \\
\text { c. Hapus Pelanggan: User memilih salah } \\
\text { satu data pelanggan. User mendapatkan } \\
\text { peringatan "apakah benar data tersebut } \\
\text { yang akan dihapus?". Jika menekan Ya } \\
\text { maka data akan terhapus dari database. }\end{array}$ & Sukses \\
\hline 3 & $\begin{array}{l}\text { Manajemen } \\
\text { Vendor }\end{array}$ & $\begin{array}{l}\text { Deksripsi: } \\
\text { Form yang digunakan untuk memanajemen } \\
\text { data vendor. } \\
\text { Prosedur Pengujian: } \\
\text { a. Tambah vendor: User menekan tombol } \\
\text { tambah vendor. User memasukan data- } \\
\text { data vendor, jika berhasil maka data akan } \\
\text { tersimpan pada database dan muncul pada } \\
\text { halaman vendor. } \\
\text { b. Ubah vendor: User memilih salah satu } \\
\text { vendor yang akan diubah datanya. User } \\
\text { kemudian mengubah data lalu menekan } \\
\text { tombol update. Jika berhasil data akan } \\
\text { terupdate pada database dan data akan }\end{array}$ & Sukses \\
\hline
\end{tabular}




\begin{tabular}{|c|c|c|c|}
\hline No & Fungsi & Keterangan & Status \\
\hline & & $\begin{array}{l}\text { terganti. } \\
\text { c. Hapus vendor: User memilih salah satu } \\
\text { data vendor. User mendapatkan } \\
\text { peringatan "apakah benar data tersebut } \\
\text { yang akan dihapus?". Jika menekan Ya } \\
\text { maka data akan terhapus dari database. }\end{array}$ & \\
\hline 4 & $\begin{array}{l}\text { Manajemen } \\
\text { Produk }\end{array}$ & $\begin{array}{l}\text { Deksripsi: } \\
\text { Form yang digunakan untuk memanajemen } \\
\text { data produk. } \\
\text { Prosedur Pengujian: } \\
\text { a. Tambah produk: User menekan tombol } \\
\text { tambah produk. User memasukan data- } \\
\text { data produk, jika berhasil maka data akan } \\
\text { tersimpan pada database dan muncul pada } \\
\text { halaman produk. } \\
\text { b. Ubah produk: User memilih salah satu } \\
\text { produk yang akan diubah datanya. User } \\
\text { kemudian mengubah data lalu menekan } \\
\text { tombol update. Jika berhasil data akan } \\
\text { terupdate pada database dan data akan } \\
\text { terganti. } \\
\text { c. Hapus produk: User memilih salah satu } \\
\text { data vendor. User mendapatkan } \\
\text { peringatan "apakah benar data tersebut } \\
\text { yang akan dihapus?". Jika menekan Ya } \\
\text { maka data akan terhapus dari database. }\end{array}$ & Sukses \\
\hline 5 & $\begin{array}{l}\text { Manajemen } \\
\text { Order }\end{array}$ & $\begin{array}{l}\text { Deksripsi: } \\
\text { Form yang digunakan untuk memanajemen } \\
\text { data order. } \\
\text { Prosedur Pengujian: } \\
\text { a. Tambah order: User menekan tombol } \\
\text { tambah order. User memasukan data-data } \\
\text { order, jika berhasil maka data akan } \\
\text { tersimpan pada database dan muncul pada } \\
\text { halaman order. } \\
\text { b. Ubah order: User memilih salah satu order } \\
\text { yang akan diubah datanya. User kemudian } \\
\text { mengubah data lalu menekan tombol } \\
\text { update. Jika berhasil data akan terupdate } \\
\text { pada database dan data akan terganti. } \\
\text { c. Hapus order: User memilih salah satu data } \\
\text { order. User mendapatkan peringatan } \\
\text { "apakah benar data tersebut yang akan } \\
\text { dihapus?". Jika menekan Ya maka data } \\
\text { akan terhapus dari database. }\end{array}$ & Sukses \\
\hline 6 & $\begin{array}{l}\text { Manajemen } \\
\text { Produksi } \\
\text { Pracetak }\end{array}$ & $\begin{array}{l}\text { Deksripsi: } \\
\text { Form yang digunakan untuk memanajemen } \\
\text { data pracetak. } \\
\text { Prosedur Pengujian: } \\
\text { a. Tambah pracetak: User menekan tombol }\end{array}$ & Sukses \\
\hline
\end{tabular}




\begin{tabular}{|c|c|c|c|}
\hline No & Fungsi & Keterangan & Status \\
\hline & & $\begin{array}{l}\text { tambah pracetak. User memasukan data- } \\
\text { data pracetak, jika berhasil maka data } \\
\text { akan tersimpan pada database dan muncul } \\
\text { pada halaman pracetak. } \\
\text { b. Ubah pracetak: User memilih salah satu } \\
\text { pracetak yang akan diubah datanya. User } \\
\text { kemudian mengubah data lalu menekan } \\
\text { tombol update. Jika berhasil data akan } \\
\text { terupdate pada database dan data akan } \\
\text { terganti. } \\
\text { c. Hapus pracetak: User memilih salah satu } \\
\text { data pracetak. User mendapatkan } \\
\text { peringatan "apakah benar data tersebut } \\
\text { yang akan dihapus?". Jika menekan Ya } \\
\text { maka data akan terhapus dari database. }\end{array}$ & \\
\hline 7 & $\begin{array}{l}\text { Manajemen } \\
\text { Produksi Proses } \\
\text { Cetak }\end{array}$ & \begin{tabular}{|l|} 
Deksripsi: \\
Form yang digunakan untuk memanajemen \\
data proses cetak. \\
Prosedur Pengujian: \\
a. Tambah proses cetak: User menekan \\
tombol tambah proses cetak. User \\
memasukan data-data proses cetak, jika \\
berhasil maka data akan tersimpan pada \\
database dan muncul pada halaman \\
proses cetak. \\
b. Ubah pracetak: User memilih salah satu \\
proses cetak yang akan diubah datanya. \\
User kemudian mengubah data lalu \\
menekan tombol update. Jika berhasil data \\
akan terupdate pada database dan data \\
akan terganti. \\
c. Hapus pracetak: User memilih salah satu \\
data pracetak. User mendapatkan \\
peringatan "apakah benar data tersebut \\
yang akan dihapus?". Jika menekan Ya \\
maka data akan terhapus dari database.
\end{tabular} & Sukses \\
\hline 8 & $\begin{array}{l}\text { Manajemen } \\
\text { Produksi } \\
\text { Finishing }\end{array}$ & \begin{tabular}{|l|} 
Deksripsi: \\
Form yang digunakan untuk memanajemen \\
data finishing. \\
Prosedur Pengujian: \\
a. Tambah proses finishing: User menekan \\
tombol tambah proses finishing. User \\
memasukan data-data finishing, jika \\
berhasil maka data akan tersimpan pada \\
database dan muncul pada halaman proses \\
finishing. \\
b. Ubah finishing: User memilih salah satu \\
finishing yang akan diubah datanya. User \\
kemudian mengubah data lalu menekan \\
tombol update. Jika berhasil data akan \\
terupdate pada database dan data akan
\end{tabular} & Sukses \\
\hline
\end{tabular}




\begin{tabular}{|c|c|c|c|}
\hline No & Fungsi & Keterangan & Status \\
\hline & & $\begin{array}{l}\text { terganti. } \\
\text { c. Hapus finishing: User memilih salah satu } \\
\text { data finishing. User mendapatkan } \\
\text { peringatan "apakah benar data tersebut } \\
\text { yang akan dihapus?". Jika menekan Ya } \\
\text { maka data akan terhapus dari database. }\end{array}$ & \\
\hline 9 & $\begin{array}{l}\text { Manajemen } \\
\text { Produksi } \\
\text { Delivery }\end{array}$ & $\begin{array}{l}\text { Deksripsi: } \\
\text { Form yang digunakan untuk memanajemen } \\
\text { data delivery. } \\
\text { Prosedur Pengujian: } \\
\text { a. Tambah proses delivery: User menekan } \\
\text { tombol tambah proses delivery. User } \\
\text { memasukan data-data delivery, jika } \\
\text { berhasil maka data akan tersimpan pada } \\
\text { database dan muncul pada halaman } \\
\text { proses delivery. } \\
\text { b. Ubah finishing: User memilih salah satu } \\
\text { delivery yang akan diubah datanya. User } \\
\text { kemudian mengubah data lalu menekan } \\
\text { tombol update. Jika berhasil data akan } \\
\text { terupdate pada database dan data akan } \\
\text { terganti. } \\
\text { c. Hapus finishing: User memilih salah satu } \\
\text { data delivery. User mendapatkan } \\
\text { peringatan "apakah benar data tersebut } \\
\text { yang akan dihapus?". Jika menekan Ya } \\
\text { maka data akan terhapus dari database. }\end{array}$ & Sukses \\
\hline \multirow[t]{2}{*}{10} & $\begin{array}{l}\text { Manajemen } \\
\text { Keuangan Kas } \\
\text { Masuk }\end{array}$ & $\begin{array}{l}\text { Deksripsi: } \\
\begin{array}{c}\text { Form yang digunakan untuk memanajemen } \\
\text { data kas masuk. }\end{array}\end{array}$ & Sukses \\
\hline & & $\begin{array}{l}\text { Prosedur Pengujian: } \\
\text { a. Tambah proses kas masuk: User menekan } \\
\text { tombol tambah proses kas masuk. User } \\
\text { memasukan data-data kas masuk, jika } \\
\text { berhasil maka data akan tersimpan pada } \\
\text { database dan muncul pada halaman proses } \\
\text { kas masuk. } \\
\text { b. Ubah finishing: User memilih salah satu kas } \\
\text { masuk yang akan diubah datanya. User } \\
\text { kemudian mengubah data lalu menekan } \\
\text { tombol update. Jika berhasil data akan } \\
\text { terupdate pada database dan data akan } \\
\text { terganti. } \\
\text { c. Hapus finishing: User memilih salah satu } \\
\text { data kas masuk. User mendapatkan } \\
\text { peringatan "apakah benar data tersebut } \\
\text { yang akan dihapus?". Jika menekan Ya } \\
\text { maka data akan terhapus dari database. }\end{array}$ & \\
\hline 11 & $\begin{array}{l}\text { Manajemen } \\
\text { Keuangan Kas } \\
\text { Keluar }\end{array}$ & $\begin{array}{c}\text { Deksripsi: } \\
\text { Form yang digunakan untuk memanajemen } \\
\text { data kas keluar. }\end{array}$ & Sukses \\
\hline
\end{tabular}




\begin{tabular}{|c|c|c|c|}
\hline No & Fungsi & Keterangan & Status \\
\hline & & $\begin{array}{l}\text { Prosedur Pengujian: } \\
\text { a. Tambah proses kas keluar: User menekan } \\
\text { tombol tambah proses kas keluar. User } \\
\text { memasukan data-data kas keluar, jika } \\
\text { berhasil maka data akan tersimpan pada } \\
\text { database dan muncul pada halaman } \\
\text { proses kas keluar. } \\
\text { b. Ubah finishing: User memilih salah satu } \\
\text { kas keluar yang akan diubah datanya. User } \\
\text { kemudian mengubah data lalu menekan } \\
\text { tombol update. Jika berhasil data akan } \\
\text { terupdate pada database dan data akan } \\
\text { terganti. } \\
\text { c. Hapus finishing: User memilih salah satu } \\
\text { data kas masuk. User mendapatkan } \\
\text { peringatan "apakah benar data tersebut } \\
\text { yang akan dihapus?". Jika menekan Ya } \\
\text { maka data akan terhapus dari database }\end{array}$ & \\
\hline
\end{tabular}

\subsection{User Acceptance Test}

Alpha testing dilakukan pada metode UAT ini. Pada tahap ini pengguna dan pengembang saling melakukan testing secara interaktif. Setelah pengujian dapat disimpulkan bahwa metode prototype menunjukan sangat membantu pengguna untuk menghasilkan website sesuai yang mereka butuhkan.

\section{SIMPULAN}

Efisien adalah salah satu kemudahan yang didapat dengan menggunakan aplikasi online ini. Penelitian ini diharapkan dapat membantu perusahaan dalam mengelola data perusahaan. Data yang dikelola akan menjadi lebih efisien, karena dapat diakses secara online dari dan kapan saja. Pengelolaan data seperti, data order, data produksi, data pengiriman, manajemen vendor, dan data keuangan dapat diakses secara online, sehingga memudahkan tim manajerial untuk memantau setiap data yang ada. Efektif merupakan kelebihan lain yang ditawarkan dari aplikasi ini, penelitian ini diharapkan akan memperluas jangkauan pemasaran dari perusahaan, sehingga juga dapat meningkatkan pendapatan perusahaan.

\section{DAFTAR PUSTAKA}

[1] P. H. P. Parsaorantua, Y. Pasoreh, and S. A. Rondonuwu, "Implementasi Teknologi Informasi Dan Komunikasi (Studi Tentang Web E Government Di Kominfo Kota Manado)," Acta Diurna, vol. VI, no. 3, 2017.

[2] S. R. Astari, R. Umar, and Sunardi, "Analisis dan perancangan sistem pengambilan keputusan dalam seleksi asisten laboratorium (1)," vol. 2018, no. November, pp. 13-20, 2018.

[3] Y. Trimarsiah and M. Arafat, "Analisis Dan Perancangan Website Sebagai Sarana," J. Ilm. MATRIK, vol. Vol. 19 No, pp. 1-10, 2017. 
[4] A. Supriyatna, "Sistem Informasi Pemesanan Jasa Percetakan Berbasis Web," Biomass Chem Eng, vol. 5, pp. 65-73, 2017.

[5] Ilyas, "Ilyas, Sistem Informasi Pencetakan Berbasis Web Pada Percetakan Ade Printing Tembilahan 1," J. Sist., vol. 2, pp. 1-14, 2013.

[6] R. Fauzi, S. Wibowo, and D. Y. Putri, "Perancangan Aplikasi Marketplace Jasa Percetakan Berbasis Website," Fountain Informatics J., vol. 3, no. 1, p. 5, 2018.

[7] Gunarso, "Pengembangan Layanan Hotel Berbasis Multimedia Pada Platform Android," Skripsi, pp. 1-15, 2013.

[8] L. Aufan, "Pemanfaatan Framework Codeigniter Dalam Pengembangan Sistem Informasi Pendataan Laporan Kerja Praktek Mahasiswa Program Studi Teknik Informatika Unsoed," Juita, vol. I, no. 2, pp. 39-44, 2010.

[9] S. Yasinta Bella Fitriana, Rusydi Umar, "Analisis Perbandingan Metode Simple Additive Weighting (SAW) Dan Metode Decison Table Pada Sistem Pendukung Keputusan," vol. 1, no. 1, pp. 158-161, 2016.

[10] R. Umar, A. Fadlil, and Y. Yuminah, "Sistem Pendukung Keputusan dengan Metode AHP untuk Penilaian Kompetensi Soft Skill Karyawan," Khazanah Inform. J. Ilmu Komput. dan Inform., vol. 4, no. 1, p. 27, 2018.

[11] U. Sekaran and R. Bougie, "Metode Pengumpulan data: Kuesioner," Metod. Penelit. untuk Bisnis Pendekatan Pengembangan-Keahlian, no. 01, p. 170, 2017.

[12] D. Purnomo, "Model Prototyping Pada Pengembangan Sistem Informasi," J. Inform. Merdeka Pasuruan, vol. 2, no. 2, pp. 54-61, 2017.

[13] G. I. Marthasari et al., "Rancang Bangun Dan Implementasi Website ECommerce Ukm Gs4 Malang Menggunakan Metode Prototyping," Sentra 2017, no. July, pp. 1-10, 2017.

[14] R. S. Pressman, Software Quality Engineering: A Practitioner's Approach, vol. 9781118592. 2014. 